\title{
Polymorphisms of selected Xenobiotic Genes contribute to the development of Papillary Thyroid Cancer susceptibility in Middle Eastern population
}

\author{
Abdul K Siraj ${ }^{1}$, Muna Ibrahim11, Maha Al-Rasheed1, Jehad Abubaker11, \\ Rong Bu${ }^{1}$, Shakaib U Siddiqui ${ }^{1}$, Fouad Al-Dayel ${ }^{2}$, Osama Al-Sanea ${ }^{3}$, \\ Abdulrahman Al-Nuaim ${ }^{4}$, Shahab Uddin ${ }^{1}$ and Khawla Al-Kuraya*1
}

\begin{abstract}
Address: ${ }^{1}$ Cancer Genomics, Research Centre, King Fahad National Center for Children's Cancer \& Research, King Faisal Specialist Hospital and Research Centre, Riyadh, Saudi Arabia, ${ }^{2}$ Department of Pathology and Laboratory Medicine, King Faisal Specialist Hospital and Research Centre, Riyadh, Saudi Arabia, ${ }^{3}$ Health Sciences Centre, Saad Specialist Hospital, Al-Khobar, Saudi Arabia and ${ }^{4}$ Department of Medicine, King Faisal Specialist Hospital and Research Centre, Riyadh, Saudi Arabia

Email: Abdul K Siraj - asiraj@kfshrc.edu.sa; Muna Ibrahim - munaelgadi@hotmail.com; Maha Al-Rasheed - mrasheed@kfshrc.edu.sa; Jehad Abubaker - jabubaker@kfshrc.edu.sa; Rong Bu - burong@hotmail.com; Shakaib U Siddiqui - nsiddiqui@kfshrc.edu.sa; Fouad AlDayel - dayelf@kfshrc.edu.sa; Osama Al-Sanea - oalsanea@saad.com.sa; Abdulrahman Al-Nuaim - ANuaim@kfshrc.edu.sa;

Shahab Uddin - shahab@kfshrc.edu.sa; Khawla Al-Kuraya* - kkuraya@kfshrc.edu.sa

* Corresponding author
\end{abstract}

Published: 5 July 2008

BMC Medical Genetics 2008, 9:6I doi:10.1186/147I-2350-9-6I
Received: 15 January 2008

Accepted: 5 July 2008

This article is available from: http://www.biomedcentral.com/I47I-2350/9/6I

(c) 2008 Siraj et al; licensee BioMed Central Ltd.

This is an Open Access article distributed under the terms of the Creative Commons Attribution License (http://creativecommons.org/licenses/by/2.0), which permits unrestricted use, distribution, and reproduction in any medium, provided the original work is properly cited.

\begin{abstract}
Background: The xenobiotic enzyme system that enables us to detoxify carcinogens exhibits identifiable genetic polymorphisms that are highly race specific. We hypothesized that polymorphisms of these genes may be associated with risk of thyroid cancer. To evaluate the role of genetic polymorphisms of xenobiotic genes in thyroid cancer, we conducted a hospital-based case-control study in Saudi population.
\end{abstract}

Methods: 223 incident papillary thyroid cancer cases and 513 controls recruited from Saudi Arabian population were analyzed for the association between polymorphisms in genes encoding folic acid metabolizing enzymes MTHFR and six xenobiotics-metabolizing enzymes including CYPIAI T380IC, C4887A, GSTPI AI578G, C2293T, GSTMI, GSTTI, NAT2 G590A, NQO*I C609T, using PCR-RELP.

Results: Among selected genes, CYPIAI C4887A genotypes CA, AA and variant allele A demonstrated significant differences and greater risk of developing thyroid cancer comparing to wild type genotype CC (CA vs. CC; $p<0.0001$, OR $=1.91,95 \% \mathrm{Cl}=1.36-2.70$, AA vs. CC; $\mathrm{P}<$ $0.001, \mathrm{OR}=3.48,95 \% \mathrm{Cl}=1.74-6.96$ and $\mathrm{CA}+\mathrm{AA}$ vs. CC; $\mathrm{p}<0.000 \mathrm{I}, \mathrm{OR}=2.07,95 \% \mathrm{Cl}=$ I.49-2.88). GSTTI null showed 3.48 times higher risk of developing thyroid cancer $(\mathrm{p}<0.000 \mathrm{I}, 95 \%$ $\mathrm{Cl}=2.48-4.88)$ while GSTMI null showed protective effect $(\mathrm{p}<0.05, \mathrm{OR}=0.72,95 \% \mathrm{Cl}=$ $0.52-0.99)$. Remaining loci demonstrated no significance with risk.

Conclusion: Of the 9 polymorphisms screened, we identified GST, GSTMI and CYPIAI C4887A, may be of importance to disease process and may be associated with papillary thyroid cancer risk in Saudi Arabian population. 


\section{Background}

Thyroid cancer is the most common endocrine malignancy, accounting for $3 \%$ of all cancers and is the eighth most common malignancy in the United States [1]. In contrast, in Kuwait, thyroid cancer ranks second, comprising $8 \%$ of all female cancers [2] and similar findings have been reported for other countries in the Gulf region [3]. Thyroid cancer is the fourth most common cancer and overall accounting for $6.1 \%$ in Saudi Arabia representing $3.8 \%$ male and $10.8 \%$ female malignant neoplasms, second to breast cancer [4]. Papillary thyroid carcinoma is the predominant type, accounting for almost all (approximately 90\%) thyroid malignancies [5]. Although the exact etiology of thyroid cancer remains unknown, exposure to ionizing radiation is the only verified cause of thyroid carcinogenesis in humans, especially when exposure occurs at young age, although dietary iodine deficiency has also been linked to this pathology [6-8]. However, individuals without previous exposure to ionizing radiation can also develop thyroid cancers, usually defined as sporadic tumors [9], suggesting that other risk factors could also be involved in the etiology of sporadic tumors.

It has also been suggested that individuals possessing a modified ability to metabolize carcinogens are at increased risk of cancer [10-12]. For this reason, five (5) families of genes encoding for enzymes controlling oxidative stress have attracted our interest CYPs (Phase I Cytochromes P450), GSTs (Phase II Glutathione-S-Transferase), NADPH (quinone oxidoreductase NQO1), NAT (N-acetyltransferases), and gene encoding folic acid metabolizing enzyme, Methylenetetrahydrofolate reductase (MTHFR).

MTHFR balances the pool of folate coenzymes in one carbon metabolism of DNA synthesis and methylation, both are implicated in carcinogenesis of many types of cancer. Previous reports concerning MTHFR gene polymorphisms suggests that individuals carrying the less active form of folate metabolizing enzyme will be at greater risk of cancer [10-12].

The N-acetyltransferases (NAT) are involved in the metabolism of drugs and environmental toxins. They catalyze the acetyltransfer from acetylcoenzyme A to an aromatic amine, heterocyclic amine or hydrazine compound. Sequence variations in the human NAT1 and NAT2 result in the production of NAT proteins with variable enzyme activity or stability, leading to slow or rapid acetylation. Therefore, genetic polymorphisms in NAT1 and NAT2 have been associated with drug-induced toxicities and disease [13-15].

NQO1 is acytosolic enzyme catalyzing a 2 electron reduction of quinone and preventing their participation in redox cycling and thus inoxidative stress [16]. Polymor- phism within NQO1 has shown to be associated with increased risk of myeloid leukemia [17], bladder carcinoma [18].

CYP1A1 catalyzes the oxidation of polycyclin aromatic hydrocarbons (PAHs) to epoxides and is inducible by PAH. Although several case control studies have reported an association between CYP1A1 polymorphism and susceptibility to a number of adult cancers, others reported no evidence of such association [19-22].

Glutathione S-transferases (GSTs) are a family of enzymes that carry out a wide range of functions in cells. GSTs also play a role in detoxification of a variety of endogenous and exogenous electrophilic compounds, such as the removal of reactive oxygen species and regeneration of Sthiolated proteins that are products of oxidative stress and the detoxification of carcinogenic compounds. In addition to this, GSTs modulate the induction of other enzymes and proteins important for cellular functions, such as DNA repair [23]. This class of enzymes is therefore important for maintaining cellular genomic integrity and as a result may play an important role in cancer susceptibility. Several studies have shown that GSTM1 0/0 is associated with an increased risk of lung, bladder, gastric, colorectal, and laryngeal cancers [24-28], although not of skin cancer development [29]. Thus carcinogenesis could be related to the absence of the functional GSTM1 alleles. In the thyroid, many studies related to genes such as $p 53$, RAS RET and thyrotropin receptor have improved our understanding of thyroid carcinogenesis [30].

We investigated the association between polymorphisms in genes encoding folic acid metabolizing enzymes MTHFR and six xenobiotics-metabolizing enzymes including CYP1A1 T3801C, C4887A, GSTP1 A1578G, GSTP1 C2293T, GSTM1, GSTT1, NAT2 G590A, NQO*1 C609T, since genetic differences in these genes are highly race specific and have never been screened in the Saudi PTC cases. We hypothesized that polymorphisms of genes responsible for drug metabolism xenobiotic genes may be associated with risk of thyroid cancer.

\section{Methods \\ Study Subjects}

Formalin fixed, paraffin embedded samples from 223 newly presenting and previously untreated Arabian patients with papillary thyroid carcinoma (PTC) were investigated. PTC patient samples $(n=223)$ were readily available from the archives of the Pathology Department at King Faisal Specialist Hospital and Research Centre (KFSHRC). The Institutional Review Board of the King Faisal Specialist Hospital and Research Centre approved the study in accordance with the Declaration of Helsinki. Diagnosis was confirmed by pathologic review using the 
diagnostic criteria defined in the WHO Classification [31] Briefly, tissue cylinders with a diameter of $0.6 \mathrm{~mm}$ were punched from representative tumor regions of each "donor" tissue block by using a home made semiautomatic robotic precision instrument as described [32]. Genomic DNA was extracted from paraffin embedded PTC tissues using the Puregene DNA isolation kit (Gentra, Minneapolis, MN) following the manufacturer's recommendations. Genotypes frequency data of GSTM1, GSTT1, CYP1A1 T3801C and C4887A, MTHFR C677T, GSTP1 A1578G and C2293T, NQO*1 C609T and NAT2 G590A for control population utilized in this report was from our previous study [33], briefly, whereby peripheral blood was obtained from age matched, 513 individual healthy blood donors of Middle Eastern Arab origin (95\% Saudi Arabians and 5\% from other Arab countries such as Jordan, Syria, Lebanon, Yemen) visiting the Blood Bank at KFSHRC, Riyadh, Saudi Arabia.

\section{Genotyping}

We first determined that the use of Hotstart Taq polymerase allowed us to apply the same PCR conditions to optimally amplify each of the variant alleles for all genes studied. PCR reactions were performed in $25 \mu \mathrm{l}$ containing $50 \mathrm{ng}$ of genomic DNA, 12.5 pmol each primer, 200 $\mu \mathrm{M}$ of each dNTPs, $2.5 \mathrm{mM} \mathrm{MgCl}_{2}$ and 0.5 units Hotstart Taq DNA Polymerase. After denaturation for 10 minutes at $95^{\circ} \mathrm{C}$, each PCR was performed for 35 cycles of 1 minute at $95^{\circ} \mathrm{C}, 1$ minute at $59^{\circ} \mathrm{C}$ and 1.5 minutes at $72^{\circ} \mathrm{C}$. The final elongation step was 10 minutes. Negative non-template controls were included in each PCR. The same aliquot of DNA was used to analyze all SNPs. PCR products were directly analyzed on a $2.5 \%$ agarose gel.

\section{MTHFR Polymorphisms}

MTHFR C677T was amplified using primers: (5-TGAAGGAGAAGGTGTCTGCGGGA-3 and 5-AGGACGGTGCGGTGAGAGTG-3), the MTHFR C677T genotypes CC (wildtype) produced one 198-bp band, MTHFR TT (homozygote mutation) produced two bands of 175-bp and 23-bp, while MTHFR C677T CT (heterozygote) samples exhibited a digestion pattern of all three bands when digested with Hinf I.

\section{CYPIAI Polymorphisms}

Using primers: (5-GGCTGAGCAATCTGACCCTA-3 and 5TAGGAGTCTTGTCTCATGCCT-3), the CYP1A1 T3801C genotypes TT (wildtype) produced a 341-bp band, CYP1A1 CC (homozygote mutation) produced two bands of 175-bp and 166-bp, while CYP1A1 T3801C TC (heterozygote) samples exhibited a digestion pattern of all three bands when digested with MSP I. CYP1A1 C4887A gene (rs1048943) was determined using primers (5-CTGTCTCCCTCTGGTTACAGGAAGC-3 and 5-TTCCACCCGTTGCAGCAGGATAGCC-3), and Bsa I was used to digest the 204-bp product: CYP1A1 C4887A CC (wildtype) produced two bands, a 138-bp and 66-bp, CYP1A1 C4887A AA (homozygote mutation) produced one band of 204bp, while CYP1A1 C4887A CA (heterozygote) samples exhibited a digestion pattern of all three bands (204-bp, 138-bp and 66-bp) when digested with Bsa I.

\section{GSTPI Polymorphisms}

Using primers: (5-GGCTCTATGGGAAGGACCAGCAGG3 and 5-GCACCTCCATCCAGAAACTGGCG-3), the GSTP1 A1578G (rs947894) genotype AA (wildtype) produced a 256-bp band, GSTP1 GG (homozygote mutation) produced two bands of 204-bp and 52-bp, while GSTP1 A1578G AG (heterozygote) samples exhibited a digestion pattern of all three bands when digested with BsmA I. Similarly, using primers: (5-CAGCAGAGGCAGCGTGTGTGC-3 and 5-CCCACAATGAAGGTCTTGCCTCC-3), the GSTP1 C2293T (rs1799811) CC (wildtype) produced two bands, a 120-bp and 97-bp, GSTP1 C2293T TT (homozygote mutation) produced one band of 217-bp, while GSTP1 C2293T CT (heterozygote) samples exhibited a digestion pattern of all three bands (217-bp, 120-bp and 97-bp) when digested with Aci I.

\section{NQO*I Polymorphisms}

NQO*1 C609T was amplified using primers: (5-AGTGGCATTCTGCATTTCTGTG-3 and 5-GATGGACTTGCCCAAGTGATG-3), the NQO*1 C609T genotypes CC (wildtype) produced two bands, a 188-bp and 85-bp band, $N Q O^{*} 1$ TT (homozygote mutation) produced three bands of 151-bp, 85-bp and 37-bp, while NQO*1 C609T CT (heterozygote) samples exhibited a digestion pattern of all four bands when digested with Hinf I.

\section{NAT2 Polymorphisms}

NAT2 G590A was amplified using primers: (5-CCTGGACCAAATCAGGAGAG-3 and 5-ACACAAGGGTTTATTTTGTTCC-3), the NAT2 G590A genotypes GG (wildtype) produced three bands, a 170-bp, 139-bp and 112-bp band, NAT2 AA (homozygote mutation) produced two bands of 309-bp and 112-bp, while NAT2 G590A GA (heterozygote) samples exhibited a digestion pattern of all four bands when digested with Taq I.

\section{GSTMI and GSTTI Polymorphisms}

The presence or absence of GSTM1 and GSTT1 was determined by multiplex PCR in which $\beta$-globin gene was coamplified as an internal control. GSTM1 was amplified using primers 5-GAACTCCCTGAAAAGCTAAAGC-3 and 5-GTTGGGCTCAAATATACGGTGG-3. Wherever present GSTM1 produced a 219-bp band along with 110-bp $\beta$ globin amplified with primers 5-ACACAACTGTGTTCACTAGC-3 and 5-CAACTTCATCCACGTTCACC-3. Similarly, GSTT1 produced 480-bp band along with 110 $\beta$-globin band. GSTT1 was amplified using primers 5-TTC- 
CTTACTGGTCCTCACATCTC-3 and 5-TCACCGGATCATGGCCAGCA-3. Absence of 219-bp band for GSTM1 or 480 -bp for GSTT1 with the presence of $110 \beta$-globin was recorded as deleted.

\section{Statistical Analysis}

Univariate analysis using Chi-square analyses (two-sided) was first performed to compare the differences in genotype and allele frequencies between case and control subjects. The odds ratio (OR) and 95\% confidence interval provide a measure for the strength of association, e.g. indicating the increase in the odds of a given benign or malignant thyroid tumor demonstrating a particular genotype compared with the control population. Statistical significance of the differences in the frequency of genotypes was assessed, applying two-sided Fisher's exact test, and odds ratios (ORs) with 95\% CI were calculated on the SPSS statistical package (version 11.0). All tests were conducted at the $\mathrm{p}<0.05$ level of significance.

\section{Results}

Tables 1, 2 provide detailed information on the frequency of the multiple genotypes analyzed. 223 PTC samples were included in this study. Initially, only 50 out of 223 PTC samples were analyzed for 9 SNPs in 7 genes (Table 1). Furthermore, comparing cases with the control study group the association between polymorphisms and the risk to develop thyroid cancer was initially assessed with 50 PTC samples and the SNP's that showed statistical significance were selected to further confirm the finding with larger number of cases analyzed $(\mathrm{n}=223)$ (Table 2$)$.

Frequencies for CYP1A1 C4887A genotypes CC, CA, AA and $\mathrm{CA}+\mathrm{AA}$ were $16.7 \%, 71.4 \%, 11.9 \%$ and $83.3 \%$ respectively and frequency of A allele was $48 \%$ when initial analysis with 50 cases was performed. Genotype CA showed 8.7-fold, AA showed 13.1-fold and CA+AA demonstrated 9.2-fold higher risk, compared with wild type (p $<0.0001)$. On the other hand, analysis of CYP1A1 T3801C showed no statistical significance (Table 1).

Although GSTP1 C2293T, genotype TT accounted for 5\% of PTC cases comparing with $1.5 \%$ of controls and showed 3.24 fold higher risk to develop thyroid cancer but did not reached to level of significance (Table 1).

Among 50 PTC cases, $67.3 \%$ were homogenous for the GSTT1 null genotype compared with $25 \%$ of controls. Consequently there was 6.24 fold increase in the risk of thyroid cancer associated with GSTT1 null genotype (OR $=6.24$ ). No significant differences were found in the frequency of other genes when 50 cases were compared with controls (Table 1).
Using our selection criteria, in particular two genes from xenobiotic metabolizing enzyme system (CYP1A1 C4887A and GSTT1) were chosen to elaborate the study with further 173 cases, since they have demonstrated high statistical significance and odds ratio when controls were compared to initially analyzed 50 cases form PTC samples. Additionally two genes, GSTM1 and NAT2 G590A, which have shown no statistical significance, were also selected for further analysis to confirm the reliability of our selection criteria. 173 further PTC cases were analyzed for these four genes and compared with control case group to assess the association between polymorphisms and the risk to develop thyroid cancer. Although the initial selection criteria was not deemed statistically powerful due to less number of samples nevertheless provided with the selection of genes to expand the study with statistically significant data. As can be seen GSTM1 and NAT2 G590A genes, demonstrated no significant association with risk estimate compared to control group even when expanded with 173 more PTC samples (tables 1 and 2).

Among selected genes, frequencies for CYP1A1 C4887A genotypes CC, CA, AA and CA+AA were 47\%, 44\%, 9\% and $53 \%$ respectively and frequency of $A$ allele was $31 \%$. Genotypes CA, AA and variant allele A demonstrated significant differences comparing to wild type genotype CC. Odds ratio showed CA has 1.9 fold, while AA has 3.4 fold and variant allele A showed 2 fold greater risk of developing thyroid cancer comparing to wild type.

GSTT1 null showed 3.48 times higher risk of developing thyroid cancer ( $\mathrm{p}<0.0001)$ while GSTM1 null showed protective effect $(\mathrm{p}<0.05, \mathrm{OR}=0.718)$. Although the GSTT1 null was risk factor $(\mathrm{OR}=3.48)$ to develop PTC (p $<0.0001$ ) but double null of GSTT1 and GSTM1 showed no statistical significance (Table 2).

We also investigated whether the prevalence of combined GSTT1 null and GSTM1 null genotype (double-null genotype) was significantly increased in PTC cases compared with controls (Table 2). Among PTC cases, 23.6\% were both GSTT1 and GSTM1 null, compared with $17.2 \%$ of controls. When individuals with both GSTT1 and GSTM1 were considered as the reference group, analysis demonstrated comparatively lower increased risk $(\mathrm{OR}=1.45)$ in individuals with the double-null genotype than that seen with GSTT1 null alone, but the results did not reach the level of significance.

\section{Discussion}

Multiple enzyme pathways are involved in detoxification of chemotherapeutic agents and/or carcinogens. Variations in GSTT1, GSTM1 and GSTP1 have been previously demonstrated to influence drug efficacy and toxicity and also to modify individual susceptibility to cancers [34-39] 
Table I: Distribution of polymorphisms in healthy population and thyroid cancer patients $(\mathbf{n}=\mathbf{5 0})$.

\begin{tabular}{|c|c|c|c|c|c|c|}
\hline Polymorphism & Genotype & Control & PTC & $\mathbf{p}^{*}$ & OR\$ & $95 \% \mathrm{Cl}$ \\
\hline \multirow[t]{4}{*}{ MTHFR C667T } & $\mathrm{CC}$ & $372(72.8 \%)$ & $30(61.2 \%)$ & & & \\
\hline & $\mathrm{CT}$ & $126(24.7 \%)$ & $18(46.15 \%)$ & 0.09 & 1.77 & $0.96-3.29$ \\
\hline & $\mathrm{TT}$ & $13(2.5 \%)$ & $\mathrm{I}(2.6 \%)$ & I & 0.95 & $0.12-7.54$ \\
\hline & $\mathrm{CT}+\mathrm{TT}$ & $139(27.2 \%)$ & $19(48.7 \%)$ & 0.10 & 1.70 & $0.92-3.11$ \\
\hline \multirow[t]{4}{*}{ CYPIAI T380IT } & TT & $327(64.2 \%)$ & $27(57.4 \%)$ & & & \\
\hline & TC & $157(30.9 \%)$ & $15(31.9 \%)$ & 0.73 & 1.16 & $0.60-2.24$ \\
\hline & $\mathrm{CC}$ & $25(4.9 \%)$ & $5(10.6 \%)$ & 0.09 & 2.42 & $0.86-6.83$ \\
\hline & $\mathrm{CC}+\mathrm{TC}$ & $182(35.8 \%)$ & $20(42.5 \%)$ & 0.35 & I...33 & $0.73-2.44$ \\
\hline \multirow[t]{4}{*}{ CYPIAI C4887A } & $\mathrm{CC}$ & $331(64.8 \%)$ & $7(16.7 \%)$ & & & \\
\hline & $\mathrm{CA}$ & $162(31.7 \%)$ & $30(71.4 \%)$ & $<0.0001$ & 8.76 & $3.77-20.36$ \\
\hline & AA & $18(3.5 \%)$ & $5(11.9 \%)$ & $<0.0001$ & 13.14 & $3.79-45.47$ \\
\hline & $C A+A A$ & $180(35.2 \%)$ & $35(83.3 \%)$ & $<0.0001$ & 9.19 & $4.00-21.12$ \\
\hline \multirow[t]{4}{*}{ GSTPI AI578G } & AA & $170(33.5 \%)$ & $18(38.3 \%)$ & & & \\
\hline & $A G$ & $27 \mid(53.5 \%)$ & $25(53.2 \%)$ & 0.74 & 0.87 & $0.46-1.65$ \\
\hline & GG & $66(13 \%)$ & $4(8.5 \%)$ & 0.45 & 0.57 & $0.19-1.75$ \\
\hline & $A G+G G$ & $337(66.5 \%)$ & $29(61.7 \%)$ & 0.52 & 0.81 & $0.44-1.5 \mid$ \\
\hline \multirow[t]{4}{*}{ GSTPI C2293T } & $\mathrm{CC}$ & $389(76.3 \%)$ & $30(75 \%)$ & & & \\
\hline & $\mathrm{CT}$ & $113(22.2 \%)$ & $8(20 \%)$ & 1 & 0.92 & $0.4 I-2.06$ \\
\hline & TT & $8(1.5 \%)$ & $2(5 \%)$ & 0.17 & 3.24 & $0.66-15.95$ \\
\hline & $\mathrm{CT}+\mathrm{TT}$ & $121(23.7 \%)$ & $10(25 \%)$ & 0.85 & 1.07 & $0.5 \mathrm{I}-2.26$ \\
\hline \multirow[t]{2}{*}{ GSTMI } & $P$ & $233(45.4 \%)$ & $24(48 \%)$ & & & \\
\hline & $\mathrm{D}$ & $280(54.6 \%)$ & $26(52 \%)$ & 0.77 & 0.90 & $0.50-1.61$ \\
\hline \multirow[t]{2}{*}{ GSTTI } & $P$ & $385(75 \%)$ & $16(32.7 \%)$ & & & \\
\hline & $\mathrm{D}$ & $128(25 \%)$ & $33(67.3 \%)$ & $<0.0001$ & 6.24 & $3.31-11.64$ \\
\hline \multirow[t]{4}{*}{ NAT2 G590A } & GG & $284(55.4 \%)$ & $19(46.3 \%)$ & & & \\
\hline & GA & $181(35.3 \%)$ & $17(4 \mid .5 \%)$ & 0.34 & $\mathrm{I} .40$ & $0.7 \mid-2.77$ \\
\hline & AA & $47(9.2 \%)$ & $5(12.2 \%)$ & 0.37 & 1.59 & $0.57-4.47$ \\
\hline & $\mathrm{GA}+\mathrm{AA}$ & $228(44.5 \%)$ & $22(53.7 \%)$ & 3.29 & 1.44 & $0.76-2.73$ \\
\hline \multirow[t]{4}{*}{ NQO*I C609T } & $\mathrm{CC}$ & $295(58.5 \%)$ & $30(61.2 \%)$ & & & \\
\hline & $\mathrm{CT}$ & $177(35.1 \%)$ & $18(36.7 \%)$ & I & I & $0.54-1.85$ \\
\hline & TT & $32(6.4 \%)$ & $\mathrm{I}(2.04 \%)$ & 0.34 & 0.31 & $0.04-2.33$ \\
\hline & $\mathrm{CT}+\mathrm{TT}$ & $209(41.5 \%)$ & $19(38.74 \%)$ & 0.76 & 0.89 & $0.49-1.63$ \\
\hline
\end{tabular}

* Statistical significance of the differences in the frequency of genotypes was assessed, applying two-sided Fisher's exact test to compare between case and control subjects.

\$The odds ratio (OR) providing a measure for the strength of association demonstrating a particular genotype compared with the control population calculated using the SPSS statistical package (version II.0).

$\mathrm{P}=$ Present and $\mathrm{D}=$ Deletion for GSTMI and GSTTI gene

however, there are scarce data specific to patients with thyroid cancer [40-46]. Host factors may contribute to an individual's risk of developing secondary cancers. Our findings suggest that polymorphisms of certain xenobiotic metabolizing enzyme genes modify the individual susceptibility to develop thyroid cancer in the Saudi population. Our findings from this hospital-based case-control study are not entirely consistent with previous published studies.
GSTs participate in the metabolism of alkylating agents, anthracyclines and steroids and variations in within these genes can significantly influence treatment outcome $[35,36]$. The different glutathione S-transferase (GST) enzymes have classically been considered as an important part of the cell defense against numerous harmful chemicals and reactive oxygen species (ROS) produced endogenously and in the environment [48-52]. Their importance is suggested by the finding that mutations in GST genes have been associated with susceptibility to various diseases, in particular with cancer [48]. 
Table 2: Distribution of Xenobiotic genes polymorphisms in healthy population and PTC cases $(n=223)$.

\begin{tabular}{|c|c|c|c|c|c|c|}
\hline Polymorphism & Genotype & Control group & PTC Cases & $\mathbf{p}^{*}$ & $\mathbf{O R}^{\$}$ & $(95 \% \mathrm{Cl})$ \\
\hline \multicolumn{7}{|l|}{ CYPIAI C4887A } \\
\hline & $\mathrm{CC}$ & $33 \mid(64.8 \%)$ & 95 (47\%) & & & \\
\hline & CA & $162(31.7 \%)$ & 89 (44\%) & $<0.0001$ & 1.91 & $(1.36-2.70)$ \\
\hline & AA & $18(3.5 \%)$ & $18(10 \%)$ & $<0.001$ & 3.48 & (1.74-6.96) \\
\hline & $C A+A A$ & $180(35.2 \%)$ & $107(53 \%)$ & $<0.0001$ & 2.07 & (1.49-2.88) \\
\hline \multicolumn{7}{|l|}{ NAT2 G590A } \\
\hline & GG & 284 (55.4\%) & 99 (50\%) & & & \\
\hline & GA & I8I (35.3\%) & 81 (4I\%) & 0.180 & 1.28 & $(0.91-1.82)$ \\
\hline & $\mathrm{AA}$ & 47 (9.2\%) & $18(9 \%)$ & 0.76 & 1.11 & $(0.61-1.98)$ \\
\hline & $\mathrm{GA}+\mathrm{AA}$ & $228(44.5 \%)$ & 99 (50\%) & 0.21 & 1.25 & $(0.90-1.73)$ \\
\hline \multicolumn{7}{|l|}{ GSTTI } \\
\hline & $P$ & 385 (75\%) & 96 (46.37\%) & & & \\
\hline & $D$ & 128 (25\%) & 111 (53.62\%) & $<0.0001$ & 3.48 & $(2.48-4.88)$ \\
\hline \multicolumn{7}{|l|}{ GSTMI } \\
\hline & $P$ & $233(45.4 \%)$ & 109 (53.7\%) & & & \\
\hline & $D$ & 280 (54.6\%) & $94(46.3 \%)$ & 0.047 & 0.72 & $(0.52-0.99)$ \\
\hline \multicolumn{7}{|l|}{ GSTMI+GSTTI } \\
\hline & $P$ & $423(82.8)$ & 159 (78.32\%) & & & \\
\hline & $D$ & 88 (17.2\%) & 48 (23.64\%) & 0.074 & 1.45 & $(0.98-2.16)$ \\
\hline
\end{tabular}

\footnotetext{
* Statistical significance of the differences in the frequency of genotypes was assessed, applying two-sided Fisher's exact test to compare between case and control subjects.

$\$$ The odds ratio (OR) providing a measure for the strength of association demonstrating a particular genotype compared with the control population calculated using the SPSS statistical package (version II.0).

$\mathrm{P}=$ Present and $\mathrm{D}=$ Deletion for GSTMI and GSTTI gene
}

The only three studies published so far on involvement of GSTT1 and GSTM1 null alleles in thyroid cancer risk were carried out in three different regions with different frequencies of GST deletion genotype in general population (Spain, Brazil and Portugal) $[45,52,53]$. Contrary to our findings the results obtained in three recently published studies $[45,52,53]$ did not show increased risk between the GST polymorphisms and papillary and follicular thyroid cancer susceptibility. We found that the GSTT1 null genotype was associated with high risk $(\mathrm{OR}=3.478$, $\mathrm{p}<$ 0.0001) of developing PTC. Although our findings, showed association between the GSTM1 null genotype with decreased risk against development of PTC $(\mathrm{OR}=$ $0.718, \mathrm{p}<0.05$ ) comparing to control group, is consistent with previous reports with other cancers [19,20,52,53] including thyroid cancer [43]. Contrary to our findings Canbay et al., in a short study with 32 thyroid samples and 44 controls demonstrated association of GSTM1 null genotype with high risk of developing thyroid cancer in patients stratified with age [46]. Other thyroid cancer studies showed that only the combination of GSTM1 and GSTT1 null inheritance [53] or only the presence of three potentially risk alleles, namely GSTM1-null, GSTT1-null and GSTP1 A1578G genotype GG [46], leads to significant increase in adjusted odds ratio for papillary and follicular thyroid cancers. These results were not confirmed by the third study conducted on a Spanish population [52]. Our data showed weak association with double null genotypes GSTT1+GSTM1, and risk of PTC $(\mathrm{OR}=1.451, \mathrm{p}=0.074)$ (Table 2). Although with limited number of cases $(n=50)$ we did not find any statistical association with GSTP1 A1578G genotypes but nonetheless our findings in PTC for GSTP1 C2293T with genotypes TT showed non-significant association with elevated risk of PTC $(\mathrm{OR}=3.242)$.

The GSTT1 and GSTM1 null allele frequency among controls in the Brazilian, Spanish and other European studies [52] demonstrated marked variation compared to ours (17.2\% vs. 5, 10.3 and 9.2\%). Thus, the differences in our finding with published data could indicate role of these genotypes distinct to Saudi population. Morari et al. [53] consistent with our data showed that papillary carcinoma patients (17\%) and follicular carcinoma patients (10\%) presented a higher prevalence of the combined GSTT1/M1 null genotype than the normal population individuals (5\%; OR 2.6; 95\% CI, 1.044-6.355; p < 0.05). Similar to others $[52,53]$ our results demonstrated higher frequency of combined GSTT1/M1 null genotype in PTC than in control group $23.6 \%$ vs. $17.2 \%$ ). In addition, the fre- 
quency of null GSTT1 in our patients was two fold higher than in control group ( $53.6 \%$ vs. $25 \%$ ).

In the present study, an increased risk of developing PTC associated with the GSTT1 null and protective effect of GSTM1 null allele was suggested, although not reaching the statistical significance but demonstrated trend towards increased risk with double, GSTT1 and GSTM1 null genotype.

CYP1A1 genes are associated with higher enzymatic inducibility. Levels of circulating hormone are affected by genetic variability, and analysis of genetic polymorphisms that influence estrogen production may provide insight into its potential role in carcinogenesis. Estrogen exerts pleotropic effects on lymphocyte activation, proliferation, cell cycle progression and apoptosis [56], factors that may influence thyroid cancer risk. Additionally depending on levels, cortisol can either suppress or stimulate immune function, so modulation of its production could potentially influence thyroid cancer risk. In our study, CYP1A1, phenotype AA demonstrated strong association with increased risk of developing PTC $(\mathrm{OR}=3.484, \mathrm{p}<0.001)$. Additionally other CYP1A1 C4887A genotypes CA (OR = $1.914, \mathrm{p}<0.0001)$ and variant allele A $(\mathrm{OR}=2.071, \mathrm{p}<$ 0.0001 ) also demonstrated two fold high risk of developing PTC compared to the wild type. Recently we also demonstrated significantly high differential expression of CYP1A1 gene in PTC compared to normal counterparts, support the notion and may suggest a possible role for estrogen and possibly other cholesterol metabolites formed via CYP1A1 C4887A in the pathogenesis of PTC [57]. Scarce data is available on the association between CYP1A1 polymorphism and increased susceptibility to thyroid cancer. Recently Bufalo et al., in an extensive study investigating CYP1A1 ( $m 1$ and $m 2$ ) role in thyroid tumorigenesis and its connection with GSTM1, GSTT1, GSTP1, GSTO1, and codon 72 of $p 53$ genotypes, demonstrated an inverse association between germline CYP1A1 inheritance and smoking with the risk of thyroid nodules and papillary carcinomas [58].

The reasons for these divergent results are not clear but are likely racial differences because the frequencies of CYP1A1, GSTT1, GSTM1, GSTP1 and NQO1 in our controls were different from those found in other studies [33]. For instance certain SNPs like CYP1A1 A4889G and GSTP1 A1578G were not in Hardy-Weinberg equilibrium in the control samples which is contradicting comparing to other population based data. In order to question the specificity of the assay and to rule out the possibility of uncompleted digestion due to inactivation of enzymes or inhibitors in digestion mixture, we repeated the assays multiple and over period of time. Consistent results were obtained demonstrating this to be the true feature in our population.

Consideration must also be given to potential limitation of the present study and that is the nature of the control subjects enrolled which weakens the study to be claimed purely case: control. Although controls were matched with respect to age but there was gender differences, with preponderance of male blood donors $(25: 1)$. While this initial documentation of allelic frequencies in the Arabs may be biased because of the nature of subjects enrolled (preponderance of male blood donors), previous reports have indicated only minimal influence of age and gender on the distribution of these polymorphisms in a given population.

Additionally, in our study PTC patient samples from paraffin embedded tissues were readily available from the archives of the Pathology Department at King Faisal Specialist Hospital and Research Centre (KFSHRC). Similarly control group was randomly selected from DNA available from peripheral blood samples at institutional Tissue Biorepository Bank at KFSHRC. It would have been ideal to analyze samples from uniform source (tissue only or peripheral blood of patients and controls) but it was not possible in our case since archival samples were used. Since genetic aberrations, that could be present in the tumor but possibly not in the "normal tissue" could confound analyses but to the best of our knowledge there are no such reports suggesting somatic mutations in studied genes in thyroid cases.

Obviously, further study with a larger sample size is needed to confirm these findings and to examine the interaction between genotypes. However, this study does provide preliminary case-control data on several polymorphisms in genes of the xenobiotic pathways and risk to develop thyroid cancer.

\section{Conclusion}

We hypothesized that polymorphisms of genes responsible for drug metabolism xenobiotic genes may be associated with risk of thyroid cancer. Of the 9 polymorphisms screened, we identified GST, GSTM1 and CYP1A1 C4887A may be of importance to this disease process. Obviously, confirmatory studies with larger sample sizes will be needed for other genes that showed no significance with risk, but these findings represent a step toward the understanding of genetic susceptibility to thyroid cancer. If these findings are confirmed, then genotypes could be incorporated into future genetic profiles of thyroid cancer risk and may serve in future cancer prevention efforts or public health responses to accompanying risk factors. 


\section{Competing interests}

The authors declare that they have no competing interests.

\section{Authors' contributions}

AKS participated in the data analysis and drafting of the manuscript; MI and MAR took part in the genotyping, managed and analyzed the data and approved the final version of the manuscript; JA and RB participated in analyzing subset of patient samples by sequencing, validating RFLP and approved the final version of the manuscript; SUS participated in collecting the clinical data analysis and approved the final version of the manuscript; FAD, OAS and AAN contributed substantially in acquisition of samples and interpretation of data and also participated in revising and formulating the content. SU participated in the concept and design of the study and approved the final version of the manuscript; KAK was responsible for the conception, funding, design and coordination of the study.

\section{Acknowledgements}

The authors' thank to Azadali Moorji and Wael Al Haqawi for technical assistance.

\section{References}

I. Jemal A, Murray T, Ward E: Cancer Statistics. CA Cancer J Clin 2005, 54:8-29.

2. Memon A, Varghese A, Suresh A: Benign thyroid disease and dietary factors in thyroid cancer: a case-control study in Kuwait. Br J Cancer 2002, 86: 1745-50.

3. Abdulmughni YA, Al Hureibi KA, Ghafoor MA, Al Wadan AH, Al Hureibi YA: Thyroid Cancer in Yemen. Saudi Med J 2004, 25:55-9.

4. Bazarbashi S, DeVol E, Young S, Al-Eid H, Arteh S: Cancer Incidence Report Saudi Arabia 1999-2000. National Cancer Registry 2004.

5. Hundahl SA, Fleming ID, Fremgen AM, Menck HR: A national cancer database report on 53,856 cases of thyroid carcinoma treated in the U. S., 1985-1995. Cancer 1998, 83:2638-2648.

6. Ron E, Lubin JH, Shore RE, Mabuchi K, Modan B, Pottern LM, Schnei$\operatorname{der} A B$, Tucker MA, Boice JD Jr: Thyroid cancer after exposure to external radiation: a pooled analysis of seven studies. Radiat Res 1995, 141:259-77.

7. Schlumberger M, Cailleux AF, Suarez HG, de Vathaire F: Irradiation and second cancers. The thyroid as a case in point. CR Acad Sci III 1999, 322:205-13.

8. Lund E, Galanti MR: Incidence of thyroid cancer in Scandinavia following fallout from atomic bomb testing: an analysis of birth cohorts. Cancer Causes Control 1999, 10:181-7.

9. Sarasin A, Bounacer A, Lepage F, Schlumberger M, Suarez HG: Mechanisms of mutagenesis in mammalian cells. Application to human thyroid tumours. C R Acad Sci III I999, 322:|43-9.

10. Laverdiere C, Chiasson S, Costea I, Moghrabi A, Krajinovic M: Polymorphism G80A in the reduced folate carrier gene and its relationship to methotrexate plasma levels and outcome of childhood acute lymphoblastic leukemia. Blood 2002, 100:3832-4.

I I. Hishida A, Matsuo K, Hamajima N, Ito H, Ogura M, Kagami Y, Taji H, Morishima Y, Emi N, Tajima K: Associations between polymorphisms in the thymidylate synthase and serine hydroxymethyltransferase genes and susceptibility to malignant lymphoma. Haematologica 2003, 88: I59-66.

12. Matsuo K, Hamajima N, Suzuki R, Ogura M, Kagami Y, Taji H, Yasue T, Mueller NE, Nakamura S, Seto M, Morishima Y, Tajima K: Methylenetetrahydrofolate reductase gene (MTHFR) polymorphisms and reduced risk of malignant lymphoma. $\mathrm{Am} J$ Hematol 2004, 77:35I-7.
13. Butcher NJ, Boukouvala S, Sim E, Minchin RF: Pharmacogenetics of the arylamine $\mathbf{N}$-acetyltransferases. Pharmacogenomics 2002 , 2:30-42.

14. Grant DM, Goodfellow GH, Sugamori K, Durette K: Pharmacogenetics of the human arylamine $\mathbf{N}$ - acetyltransferases. Pharmacology 2000, 61 :204-2 II.

15. Hein DW, Doll MA, Fretland AJ, Leff MA, Webb SJ, Xiao GH, Devanaboyina US, Nangju NA, Feng Y: Molecular genetics and epidemiology of the NATI and NAT2 acetylation polymorphisms. Cancer Epidemiol Biomarkers Prev 2000, 9:29-42.

16. Venugopal R, Jaiswal AK: NrfI and Nrf2 positively and c-Fos and Fral negatively regulate the human antioxidant response element-mediated expression of $\mathbf{N A D}(\mathbf{P}) \mathrm{H}: q u i n o n e$ oxidoreductase I gene. Proc Natl Acad Sci USA 1996, 93:|4960-5.

17. Larson RA, Wang Y, Banerjee M, Wiemels ], Hartford C, Le Beau MM, Smith MT: Prevalence of the inactivating 609C-->T polymorphism in the NAD(P)H:quinone oxidoreductase (NQOI) gene in patients with primary and therapy-related myeloid leukemia. Blood 1999, 94:803-7.

18. Schulz WA, Krummeck A, Rösinger I, Schmitz-Dräger BJ, Sies H: Predisposition towards urolithiasis associated with the NQOI null-allele. Pharmacogenetics 1998, 8:453-4.

19. Sarmanova J, Benesova K, Gut I, Nedelcheva-Kristensen V, Tynkova L, Soucek P: Genetic polymorphisms of biotransformation enzymes in patients with Hodgkin's and non-Hodgkin's lymphomas. Hum Mol Genet 200I, I 0: I 265-73.

20. Kerridge I, Lincz L, Scorgie F, Hickey D, Granter N, Spencer A: Association between xenobiotic gene polymorphisms and nonHodgkin's lymphoma risk. Br I Haematol 2002, I I 8:477-8I.

21. Aydin-Sayitoglu M, Hatirnaz O, Erensoy N, Ozbek U: Role of CYP2D6, CYPIAI, CYP2EI, GSTTI, and GSTMI genes in the susceptibility to acute leukemias. Am J Hematol 2006, 8 I :62-70.

22. Pakakasama S, Mukda E, Sasanakul W, Kadegasem P, Udomsubpayaku $U$, Thithapandha A, Hongeng S: Polymorphisms of drug-metabolizing enzymes and risk of childhood acute lymphoblastic leukemia. Am J Hematol 2005, 79:202-5.

23. Hayes JD, Pulford DJ: The glutathione S-transferase supergene family: regulation of GST and the contribution of the isoenzymes to cancer chemoprotection and drug resistance. Crit Rev Biochem Mol Biol 1995, 30:445-600.

24. Lin HJ, Han CY, Bernstein DA, Hsiao W, Lin BK, Hardy S: Ethnic distribution of the glutathione transferase Mu I-I (GSTMI) null genotype in 1473 individuals and application to bladder cancer susceptibility. Carcinogenesis 1994, I 5: I077-8I.

25. Hirvonen A, Husgafvel-Pursiainen K, Anttila S, Vainio $H$ : The GSTMI null genotype as a potential risk modifier for squamous cell carcinoma of the lung. Carcinogenesis 1993, |4:|479-8|

26. Oude Ophuis MB, van Lieshout EMM, Roelofs HMJ, Peters WHM, Manni J): Glutathione S-transferase $M I$ and $T I$ and cytochrome $\mathbf{P 4 5 0}$ IAI polymorphisms in relation to the risk for benign and malignant head and neck lesions. Cancer 1998 , 82:936-43.

27. Katoh T, Nagata N, Kuroda $\mathrm{Y}$, Itoh H, Kawahara A, Kuroki N, Ookuma R, Bell DA: Glutathione S-transferase MI (GSTMI) and TI (GSTTI) genetic polymorphism and susceptibility to gastric and colorectal adenocarcinoma. Carcinogenesis 1996 , I 7: | 855-9.

28. Brockmöller J, Cascorbi I, Kerb R, Roots I: Combined analysis of inherited polymorphisms in arylamine $\mathbf{N}$-acetyltransferase 2, glutathione S-transferases $M I$ and TI, microsomal epoxide hydrolase, and cytochrome $\mathbf{P 4 5 0}$ enzymes as modulators of bladder cancer risk. Cancer Res 1996, 56:39| 5-25.

29. Shanley SM, Chenevix-Trench G, Palmer J, Hayward N: Glutathione S-transferase GSTMI null genotype is not overrepresented in Australian patients with nevoid basal cell carcinoma syndrome or sporadic melanoma. Carcinogenesis 1995, 16:2003-4.

30. Farid NR: Molecular pathogenesis of thyroid cancer: the significance of oncogenes, tumor suppressor genes, and genomic instability. Exp Clin Endocrinol Diabetes 1996, I 04: I- I 2.

31. De Lellis RA, Lloyd RV, Heitz PU: Tumors of endocrine organs. In Pathology and Genetics Edited by: Eng. WHO Classification of Tumors, IARC press, Lyon; 2004 
32. Simon R, Sauter G: Tissue micro arrays for miniaturized high throughput molecular profiling of tumors. Exp Hematol 2002, 30: $1365-1372$.

33. Bu R, Gutierrez MI, Al-Rasheed M, Belgaumi A, Bhatia K: Variable drug metabolism genes in Arab population. Pharmacogenomics J 2004, 4:260-6.

34. Krajinovic M, Labuda D, Mathonnet G, Labuda M, Moghrabi A, Champagne J, Sinnett D: Polymorphisms in genes encoding drugs and xenobiotic metabolizing enzymes, DNA repair enzymes, and response to treatment of childhood acute lymphoblastic leukemia. Clin Cancer Res 2002, 8:802-10.

35. Davies SM, Robison LL, Buckley JD, Tjoa T, Woods WG, Radloff GA, Ross JA, Perentesis JP: Glutathione S-transferase polymorphisms and outcome of chemotherapy in childhood acute myeloid leukemia. J Clin Oncol 200I, I 9:1279-I287.

36. Anderer G, Schrappe M, Brechlin AM, Lauten M, Muti P, Welte K, Stanulla M: Polymorphisms within glutathione S-transferase genes and initial response to glucocorticoids in childhood acute lymphoblastic leukaemia. Pharmacogenetics 2000, 10:715-726

37. Chiusolo P, Reddiconto G, Casorelli I, Laurenti L, Sora F, Mele L, Annino L, Leone G, Sica S: Preponderance of methylenetetrahydrofolate reductase C677T homozygosity among leukemia patients intolerant to methotrexate. Ann Oncol 2002 I3:1915-1918.

38. Naoe T, Takeyama K, Yokozawa T, Kiyoi H, Seto M, Uike N, Ino T, Utsunomiya A, Maruta A, Jin-nai I, Kamada N, Kubota Y, Nakamura H, Shimazaki C, Horiike S, Kodera Y, Saito H, Ueda R, Wiemels J, Ohno R: Analysis of genetic polymorphism in NQOI, GSTMI, GST-TI, and CYP3A4 in 469 Japanese patients with therapy-related leukemia/myelodysplastic syndrome and de novo acute myeloid leukemia. Clin Cancer Res 2000, 6:409I-4095.

39. Allan JM, Wild CP, Rollinson S, Willett EV, Moorman AV, Dovey G], Roddam PL, Roman E, Cartwright RA, Morgan GJ: Polymorphism in glutathione S-transferase $P I$ is associated with susceptibility to chemotherapy-induced leukemia. Proc Natl Acad Sci USA 2001, 98: I I592-II597.

40. Marciniak P, Drobnik K, Ziemnicka K, Gut P, Słomski R, Sowiński ]: Transferase S-glutathione class pi gene (GSTPI) polymorphism in thyroid cancer patients. Endokrynol Pol 2006 57:509-15. Polish.

41. Ho T, Zhao C, Zheng R, Liu Z, Wei Q, Sturgis EM: Glutathione Stransferase polymorphisms and risk of differentiated thyroid carcinomas: a case-control analysis. Arch Otolaryngol Head Neck Surg 2006, I32:756-6I.

42. Hernández A, Xamena N, Gutiérrez S, Velázquez A, Creus A, Surrallés J, Galofré P, Marcos R: Basal and induced micronucleus frequencies in human lymphocytes with different GST and NAT2 genetic backgrounds. Mutat Res 2006, 606:।2-20.

43. Stankov K, Landi S, Gioia-Patricola L, Bonora E, Volante M, Papotti M, Romeo G: GSTTI and MI polymorphisms in Hürthle thyroid cancer patients. Cancer Lett 2006, 240:76-82.

44. Granja F, Morari J, Morari EC, Correa LA, Assumpção LV, Ward LS: GST profiling may be useful in the screening for thyroid nodule malignancy. Cancer Lett 2004, 209:129-37.

45. Gaspar J, Rodrigues S, Gil OM, Manita I, Ferreira TC, Limbert E, Gonçalves L, Pina JE, Rueff J: Combined effects of glutathione Stransferase polymorphisms and thyroid cancer risk. Cancer Genet Cytogenet 2004, 1 5 1:60-7.

46. Canbay E, Dokmetas S, Canbay EI, Sen M, Bardakci F: Higher glutathione transferase GSTMI 0/0 genotype frequency in young thyroid carcinoma patients. Curr Med Res Opin 2003, 19:102-6.

47. Tew KD: Glutathione-associated enzymes in anticancer drug resistance. Cancer Res 1994, 54:4313-4321.

48. Strange RC, Spiteri MA, Ramachandran S, Fryer AA: Glutathione-Stransferase family of enzymes. Mutat Res 200I, 482:2I-26.

49. Strange RC, Jones PW, Fryer AA: Glutathione S-transferase: genetics and role in toxicology. Toxicol Lett 2000, | | 2- | | 3:357-363.

50. Landi S: Mammalian class theta GST and differential susceptibility to carcinogens: a review. Mutat Res 2000, 463:247-283.

5I. Raza H, Robin MA, Fang JK, Avadhani NG: Multiple isoforms of mitochondrial glutathione S-transferases and their differential induction under oxidative stress. Biochem J 2002, 366:45-55.
52. Hernández A, Céspedes W, Xamena N, Surrallés J, Creus A, Galofré $P$, Marcos R: Glutathione S-transferase polymorphisms in thyroid cancer patients. Cancer Lett 2003, 190:37-44.

53. Morari CE, Leite JLP, Granja F, da Assumpção LV, Ward LS: The nul genotype of glutathione S-transferase $M I$ and $T I$ locus increases the risk for thyroid cancer. Cancer Epidemiol Biomarkers Prev 2002, I I: |485-|488.

54. Rollinson S, Levene AP, Mensah FK, Roddam PL, Allan JM, Diss TC, Roman E, Jack A, MacLennan K, Dixon MF, Morgan GJ: Gastric marginal zone lymphoma is associated with polymorphisms in genes involved in inflammatory response and antioxidative capacity. Blood 2003, 102:1007-II.

55. Chiu BC, Kolar C, Gapstur SM, Lawson T, Anderson JR, Weisenburger DD: Association of NAT and GST polymorphisms with non-Hodgkin's lymphoma: a population-based case-control study. Br J Haematol 2005, I 28:6 I 0-5

56. Grimaldi CM, Cleary J, Dagtas AS, Moussai D: Diamond B. Estrogen alters thresholds for B cell apoptosis and activation. J Clin Invest 2002, I 09: 1625-33.

57. Siraj AK, Bavi P, Abubaker J, Jehan Z, Sultana M, Al-Dayel F, Al-Nuaim A, Alzahrani A, Ahmed M, Al-Sanea O, Uddin S, Al-Kuraya KS: Genome-wide expression analysis of Middle Eastern papillary thyroid cancer reveals c-MET as a novel target for cancer therapy. J Pathol 2007, 2 I 3:190-9.

58. Bufalo NE, Leite JL, Guilhen AC, Morari EC, Granja F, Assumpcao LV, Ward LS: allelic variants. Endocr Relat Cancer 2006, I 3: I I 85-93.

\section{Pre-publication history}

The pre-publication history for this paper can be accessed here:

http://www.biomedcentral.com/1471-2350/9/61/prepub

Publish with BioMed Central and every scientist can read your work free of charge

"BioMed Central will be the most significant development for disseminating the results of biomedical research in our lifetime. "

Sir Paul Nurse, Cancer Research UK

Your research papers will be:

- available free of charge to the entire biomedical community

- peer reviewed and published immediately upon acceptance

- cited in PubMed and archived on PubMed Central

- yours - you keep the copyright

Submit your manuscript here:

http://www.biomedcentral.com/info/publishing_adv.asp
BioMedcentral 